NBER WORKING PAPER SERIES

\title{
THE RISK OF OUT-OF-POCKET HEALTH CARE EXPENDITURE AT END OF LIFE
}

\author{
Samuel Marshall \\ Kathleen M. McGarry \\ Jonathan S. Skinner \\ Working Paper 16170 \\ http://www.nber.org/papers/w16170
}

\author{
NATIONAL BUREAU OF ECONOMIC RESEARCH \\ 1050 Massachusetts Avenue \\ Cambridge, MA 02138 \\ July 2010
}

This research was supported by the U.S. Social Security Administration through grant \#10-P 98363-1-05 to the National Bureau of Economic Research as part of the SSA Retirement Research Consortium. We are grateful to Michael Hurd and Susann Rohwedder for helpful comments and to Kathy Stroffolino for research assistance. The findings and conclusions expressed are solely those of the author(s) and do not represent the views of SSA, any agency of the Federal Government, or the NBER. McGarry also acknowledges financial support from the NIA through grant number R01AG16593 and Skinner through PO1AG19783. The views expressed herein are those of the authors and do not necessarily reflect the views of the National Bureau of Economic Research. The end-of-life data will be available in STATA and SAS format on www.dartmouth.edu/ jskinner

NBER working papers are circulated for discussion and comment purposes. They have not been peerreviewed or been subject to the review by the NBER Board of Directors that accompanies official NBER publications.

(C) 2010 by Samuel Marshall, Kathleen M. McGarry, and Jonathan S. Skinner. All rights reserved. Short sections of text, not to exceed two paragraphs, may be quoted without explicit permission provided that full credit, including $(\mathcal{O}$ notice, is given to the source. 
The Risk of Out-of-Pocket Health Care Expenditure at End of Life

Samuel Marshall, Kathleen M. McGarry, and Jonathan S. Skinner

NBER Working Paper No. 16170

July 2010

JEL No. I1,I12,I29,I31,J10

\begin{abstract}
$\underline{\text { ABSTRACT }}$
There is conflicting evidence on the importance of out-of-pocket medical expenditures as a risk to financial security, particularly at older ages. We revisit this question, focusing on health care spending near the end of life using data from the Health and Retirement Study for the years 1998-2006. We address difficulties with missing values for various categories of expenditures, outliers, and variations across individuals in the length of the reporting period. Spending in the last year of life is estimated to be $\$ 11,618$ on average, with the 90 th percentile equal to $\$ 29,335$, the 95 th percentile $\$ 49,907$, and the 99 th equal to $\$ 94,310$. These spending measures represent a substantial fraction of liquid wealth for decedents. Total out-of-pocket expenditures are strongly positively related to wealth and weakly related to income. We find evidence for a mechanism by which wealth could plausibly buy health: large expenditures on home modifications, helpers, home health care, and higher-quality nursing homes, which have been shown elsewhere to improve longevity.
\end{abstract}

Samuel Marshall

Department of Economics

Dartmouth College

Hanover, NH 03755

samuel.marshall@dartmouth.edu

Kathleen M. McGarry

Department of Economics

University of California, Los Angeles

Los Angeles, CA 90095-1477

and NBER

mcgarry@econ.ucla.edu
Jonathan S. Skinner

Department of Economics

6106 Rockefeller Hall

Dartmouth College

Hanover, NH 03755

and NBER

jonathan.skinner@dartmouth.edu 


\section{Introduction}

The financial impact of catastrophic out-of-pocket health care expenditures appears with alarming frequency in the national media (e.g., Trejos, 2008; New York Times, 2008), and there is strong evidence that average out-of-pocket expenditures are growing over time (Paez, et al., 2009). Most recently, Webb and Zhivan (2010) using the Health and Retirement Study (HRS) data, estimate that 5 percent of households now retiring may face out-of-pocket medical expenses of one-half million dollars or more. The rapid erosion of employer-provided retiree health insurance for current baby boomers and forecasted increases in health care costs will likely make out-of-pocket burdens even larger in the years to come (Fronstin, 2006).

However, despite the anecdotal evidence and repeated stories in the popular press, these out-of-pocket expenditures are often elusive and difficult to uncover in survey data. McGarry and Schoeni (2005) reported just \$2,500 average spending per year in the Health and Retirement Study (HRS) for people who were not near death and French and Jones (2004) found that only a very small fraction of households experience catastrophic health care shocks. More recently, De Nardi, French, and Jones (2010) found evidence of high out-of-pocket expenditures, but these arise among single people at very old ages and among high income households.

We return to these issues using data from the Health and Retirement Study (HRS) from 1998-2006 to understand better the distribution and risk of out-of-pocket medical expenses as people approach death. There are several challenges in measuring the empirical risks arising from such costs. First, there are a large number of non-responses or bracketed responses where proxy respondents - typically children or spouses of the deceased - don't know the exact amount of spending but provide a range (say nursing home expenses between $\$ 2,000$ and $\$ 10,000$, or more than $\$ 25,000)$. Imputations in these cases are clearly necessary, but made difficult by the 
sparseness of the data in some ranges on a year by year basis. We therefore harness continuous data from all six waves (1998-2006) of the HRS to develop more robust imputations.

Second, we adjust for a bias in measuring the variation or "risk" of out-of-pocket spending that arises because of the HRS survey design. Core surveys are fielded every two years and an exit survey is administered to proxies after the death of a respondent. Most questions in the exit interview ask about spending for the period of time elapsed between the last interview and the date of death, so expenditures will vary with the time to death. For people who happen to die soon after their last (core) interview, spending will be relatively low, while for those who survive for nearly the entire two year window, expenditures will be large. Although measures of average expenditures in the sample may be unbiased, the variable reporting period will tend to overstate the variance and inferences drawn from the tails of the distribution will be invalid. We correct for these biases by normalizing spending quantiles (and means) to a common 12-month period. ${ }^{1}$ We also pay particular attention to the extent to which spending rises in the last few months of life - a period of time often missed in traditional survey questionnaires - and adjust our scaling appropriately.

Third, we quantify the importance of large reported "outlier" measures for out-of-pocket spending paying considerable attention to potential reporting and coding errors. We walk the fine line between Type 1 error - dropping a large reported spending amount when it is in fact true, and Type 2 error - accepting a large reported value as fact when the respondent (or proxy) misunderstood the question or misreported the response. Rather than exclude individuals who have signaled that they are high-cost, we instead set monthly limits on what costs could

\footnotetext{
${ }^{1}$ Goldman and Zissimopoulos (2004) also use this quantile approach to examine the distribution of spending that controls for observable factors.
} 
reasonably be and cap expenditures at these limits. As well, we consider sensitivity analysis to outliers by capping amounts at different percentiles of spending. We note that the correct treatment of these rare and potentially large spending events is particularly important for health care costs, because it is just such high-cost events that are disproportionately important for financial security. We are reassured by finding that our HRS aggregate estimates of out-ofpocket spending for ages 65 and over agree well with estimates from the National Medical Expenditures Accounts (Hartman et al., 2004). ${ }^{2}$

Finally, we consider the normative implications of out-of-pocket spending by considering what types of outlays are most closely associated with wealth and income. De Nardi, French, and Jones (2010) have shown that out-of-pocket spending is highly dependent on income and we seek to assess the extent to which this pattern represents spending on consumption above and beyond medical expenditures_-say purchasing plush living arrangements in a high end assisted care facility—rather than spending for additional medical attention.

The results suggest that out-of-pocket expenditures near death are considerable, with an average of $\$ 12,120$ (in 2006 dollars) per person in our sample, or $\$ 11,618$ when scaled to represent the last year of life. However, there is considerable variance, with the $12-$ month $90^{\text {th }}$ percentile equal to $\$ 29,335$ and the $99^{\text {th }}$ percentile equal to $\$ 94,310$.

Where is all this spending going? The largest single category is nursing home and hospital expenditures, which average $\$ 4,731$ in the last year of life, of which about two-thirds is for nursing home care. Not surprisingly, the distribution of expenses is highly skewed, with a

\footnotetext{
${ }^{2}$ Hurd and Rohwedder (2009) reach different conclusions, suggesting that the HRS survey may overstate out-ofpocket spending relative to other surveys of health care spending such as the Medical Expenditure Panel Survey (MEPS). We explore this issue below.
} 
median of zero, a $95^{\text {th }}$ percentile of $\$ 27,770$, and a $99^{\text {th }}$ percentile of $\$ 75,902$. Other important sources of spending are for insurance $(\$ 1,746)$, prescription drugs $(\$ 1,496)$, home health care and helpers (\$1,966 combined), and "non-medical" spending to make houses accessible (\$721).

Out-of-pocket expenditures are higher for high-income quartiles $(\$ 14,269$ versus $\$ 9,046$ for the lowest quartile of income), but the partial impact of income on out-of-pocket spending is diminished considerably in a regression model. Differences in spending by wealth quartile are much larger than income differences with spending in the top wealth quintile equal to $\$ 18,232$ compared to $\$ 7,173$ in the bottom. These differences appeared to be driven mostly by greater spending for nursing homes, as well as for helpers, home health care, and other sources of spending that likely help maintain the independence of people living at home.

Our results are therefore consistent with a more nuanced version of the two extreme stories of out-of-pocket spending noted above. Health care expenditures represent a numerically large and potentially important drain on financial resources, particularly for households as time of death nears. However, the large wealth-elasticity (and more modest income-elasticity) suggests that some of this spending may serve to "buy" independence or represent other forms of consumption. This spending is likely to include a health component; evidence presented elsewhere suggests that these additional services could themselves have a positive impact on health outcomes (McCorkle, et al., 2000; Mor, et al., 2004), pointing to one mechanism by which wealth could buy health. ${ }^{3}$

\footnotetext{
${ }^{3}$ See Smith (1999) for a comprehensive discussion of the relationship between health and economic resources.
} 


\section{Evidence on Out-of-Pocket Health Care Expenditures}

There is mixed evidence on how out-of-pocket medical expenditures affect financial security. Perhaps the most publicized study, Himmelstein et al. (2005), was based on a survey of households which had gone through bankruptcy hearings. Roughly half of the sample cited outof-pocket expenditures as a possible cause of their bankruptcies, suggesting that out-of-pocket medical expenses are extremely burdensome. However, the survey defined relevant expenditures as expenditures of $\$ 1000$ or more. And, as Dranove and Millenson (2006) point out, this is not a very high barrier, and many households spend more for their annual insurance premiums alone. Using an alternative definition, Dranove and Millenson estimate a more plausible yet still sizeable figure, attributing up to 17 percent of all bankruptcies, at least in part, to out-of-pocket medical expenses. A Commonwealth Fund report (Merlis et al., 2006) highlighting the "growing strain" of out-of-pocket expenditures on family budgets found that just 11 percent of households had expenses exceeding $10 \%$ of income. We note, however, that even many of these "large" expenditures may have little effect on lifetime well-being if they are limited to an isolated year. A large part of the burden is likely to stem from repeatedly high health care costs.

Conversely, several studies have found larger levels of out-of-pocket spending in the Medicare population. Although Medicare provides nearly universal coverage for people 65 and over, there are substantial gaps in that coverage. For many, these gaps are filled by privately purchased "medigap" insurance or by retiree health insurance. While these supplemental plans offer relatively complete coverage of the standard Medicare deductibles and copayments, ${ }^{4}$ there

\footnotetext{
4 Medicare requires a modest deductible for doctor visits and a copayment for costs beyond this amount. Medicare does not cover the cost of the first day of hospital care, requires a significant copayment for days 61-90 and covers
} 
are important limitations to the protections provided by such policies, particularly the coverage of long term care needs. Even for individuals with the most generous "medigap" policies, both home health care services and nursing home stays must be paid for out of pocket unless the individual qualifies for benefits from the means-tested Medicaid program or purchases a separate (and expensive) long term care insurance policy. ${ }^{5}$

Gaps in the coverage of acute medical needs are likely to become increasingly important as the fraction of firms offering retiree health insurance falls. The Kaiser Foundation estimates that among large firms the percentage providing retiree coverage has fallen from 66 percent in 1988 to 31 percent in $2008 .{ }^{6}$ Among all firms, the percentage offering retiree health insurance is substantially lower with an estimated 13 percent providing retiree coverage in 2002 and likely even less today. Retirees without employer-provided coverage must purchase a medigap policy on their own, which can cost up to $\$ 200$ a month for a 65 year old. Fronstin (2006) estimates that in present-value terms someone retiring at age 65 a decade hence could need as much as $\$ 400,000$ to cover these premiums. These studies suggest that the rise in health care cost growth, coupled with the erosion of retiree insurance from employers, will lead to rapid growth in out-ofpocket expenses even if current costs are not so large.

Finally, even with relatively generous health care coverage and supplemental policies, an individual may incur substantial non-medical costs associated with a health condition. Items like

nothing for days beyond 90 (after a fixed lifetime "reserve" of 60 days is used). For those with long hospital stays and no other coverage, these costs can be substantial. Perhaps most importantly, Medicare covers neither home health care nor nursing home expenses except for brief periods of medically needed care (rehabilitation) following a hospital stay.

${ }^{5}$ Only 10 percent of the elderly have purchased long term care insurance (Finkelstein and McGarry, 2005).

${ }^{6}$ http://ehbs.kff.org/images/abstract/7814.pdf. The figure of 66 percent is for large firms (200 or more employees) that offer health insurance to those currently working. Ninety-nine percent of large firms offer health insurance. 
handicap ramps, grab bars and food to meet special dietary needs, can be expensive and must typically be borne by the individual himself.

Despite these insurance gaps, previous studies have often failed to find very large health care spending "shocks." For example, Goldman and Zissimopoulos (2003) found median out-ofpocket spending among HRS respondents over a two-year period of just $\$ 920$, with even the $95^{\text {th }}$ percentile of out-of-pocket expenditures reaching just $\$ 7,000$ - a significant amount for sure, but less than one might fear for the upper tail of the distribution. However, the Goldman and Zissimopoulus estimates do not include the end of life cohorts, and their data are from the 1998 survey when health care generally was less expensive than it might be today. ${ }^{7}$ By contrast, we focus solely on the end-of-life "exit" sample.

Most recently, De Nardi, French, and Jones (2010) quantified expected out-of-pocket expenditures in the HRS for single elderly households and found elevated spending associated with high levels of income, particularly among the very old (e.g., those age 90 and above). For example, for 95 -year olds in the top income quintile, the estimated average spending was nearly $\$ 16,000$. (Expenditures in the lower part of the income distribution are likely to be lower in part because of the important role played by Medicaid in paying for nursing home and home health care for the elderly.) De Nardi et al. showed further that the risk of high out-of-pocket expenditures helped to explain observed wealth accumulation, particularly among higher-income households who are unlikely to qualify for Medicaid coverage and may want to protect themselves against potentially burdensome long term care needs.

\footnotetext{
7 The original cohort samples in the HRS were drawn from the non-institutionalized population, so in the early years of the study we would expect the sample to be healthier-than-average . Over time, the HRS cohorts will come to resemble the elderly population more closely as some of the sample transition into nursing homes.
} 
Webb and Zhivan (2010) consider out-of-pocket risks in a dynamic model. Using the HRS data, they simulate potential spending outcomes for hypothetical 65 -year-olds extending out to their (uncertain) deaths, and find very large levels of uninsured risk: their $95^{\text {th }}$ percentile household faces a present value of $\$ 311,000$ in health care spending, or $\$ 570,000$ when adding in the cost of long-term care. However, these estimates likely overstate the true risk for two reasons. First, to capture the true risk of spending absent an insurance safety net, they assume that individuals never receive Medicaid benefits. Yet for many people who simply cannot afford the cost of care, Medicaid represents a feasible if not preferred option (Ameriks et al., 2010). The potential value of Medicaid may also affect lifetime savings and distort the perception of available resources (Hubbard, Skinner and Zeldes, 1995). And second, some of the modeled "risk" may also reflect the income or wealth elasticity of spending on health care, independent of health shocks. That is, the top $5^{\text {th }}$ percentile of spending is likely to include both people who are very sick and people who are very wealthy and who choose to consume a great deal of expensive health services. And while Webb and Zhivan (2010) do not find that their results are sensitive to outliers, we acknowledge that outliers may be more of an issue in end-of-life care, a topic to which we return below.

Finally, Hurd and Rohwedder (2009) have suggested an alternative explanation for why the risk of out-of-pocket expenditures may be overstated in studies using the HRS - that the expenditures reported in the survey itself are biased upward. They address this concern in two ways. First, they show that for the small group of people who report very high out-of-pocket spending, many do not have enough household income or wealth to pay these expenses. The problem of measurement error, however, is endemic in wealth and income, and family contributions to medical bills may be poorly captured in the survey. It is thus difficult to 
determine why the budget constraint appears to be violated — whether it is the medical expenditures that are mis-measured or the resources themselves.

The second objection raised by Hurd and Rohwedder is that aggregate spending in the HRS appears to be too high - as much as $60 \%$ overstated -- relative to other surveys such as the Medicare Expenditure Panel Survey (MEPS) and the Medicare Current Beneficiary Survey (MCBS). It is true that the MEPS and the MCBS are much better than the HRS in measuring all costs paid on behalf of the individual (i.e. both out-of-pocket costs and those insurance payments which would normally be invisible to all but very alert patients who check their insurance company paperwork). However, with respect to out-of-pocket costs in particular, the HRS asks about specific types of expenditures in more detail than do these other surveys, and allows people who are unsure about actual dollar amounts to provide a range for the expense-leading to more complete reporting. (For example, the HRS asks who helps the respondent with various tasks and whether and how much helpers are paid, providing a more accurate measure of the cost of in-home assistance than elsewhere.)Thus, there is the real possibility that rather than overestimating expenses, the HRS simply captures expenses not measured in other surveys.

Furthermore, the MEPS and MCBS are both known to miss important components of out-of-pocket spending, while French and Jones (2004) found that HRS out-of-pocket spending was close to aggregate estimates after corrections for underreporting. More recently, Hartman et al. (2007) reported age-specific spending measures using the National Medical Expenditures Accounts (NMEA), which also adjusts for underreported components of out-of-pocket spending from the other survey data. Their estimate of per capita spending for the over-65 population in 
2003/2004 was $\$ 2,170$ on average. ${ }^{8}$ Defining the 2004 HRS Core data in an equivalent manner yields a nearly identical annual estimate of $\$ 2,151 .{ }^{9}$ Including the sample of HRS respondents who died in 2004 (net of insurance payments and non-medical payments) brings the aggregate to $\$ 2,347$ per capita, just 8 percent above the NMEA estimate. ${ }^{10}$ Based on these figures, we do not believe there isevidence of a strong upward bias in the HRS out-of-pocket expenditures, a result echoed in Goldman and Zissimopoulos (2010). Still, as Hurd and Rohwedder (personal communication) have pointed out, the national estimates of age-specific spending may themselves be subject to measurement error, making it difficult to determine a "gold-standard." Finally, while the aggregates constructed from the HRS data may be approximately correct, the components of spending (in particular nursing home versus non-nursing home spending) may be measured with error (Sing, et al., 2006).

\section{Data}

Our data for this task come from the Health and Retirement Study (HRS). The HRS is a large panel survey that began in 1992 with a nationally representative sample of the population

\footnotetext{
${ }^{8}$ This estimate interpolates between 2002 and 2004 to estimate 2003 spending, and then averages 2003 and 2004 spending to match up with the two-year horizon of the HRS.

${ }^{9}$ This estimate uses similar imputations to those reported below. To adjust for the 2-year sample frame, we divide total out-of-pocket spending (net of insurance) by the number of months since the last interview, and then multiply this per-month measure by 12 .

${ }^{10}$ While end-of-life spending risk is large at an individual level, it does not add as much to the aggregate estimate both because only a small fraction of the sample dies in any year and because those who do die are alive for (on average) just 6 months. Our estimate of $\$ 2,347$ was created by assuming that the 2004 core interview was conducted on December 31, 2004, and included spending in the prior 12 months for those interviewed in the core survey, plus spending for the sample of people who had died in 12 months prior to the interview. There were 517 deaths and their average spending for the calendar year was $\$ 6,633$.
} 
born between 1931 and 1941. These original respondents have been interviewed biennially ever since with the most recent data collected in 2008. ${ }^{11}$ A separate cohort (the AHEAD cohort) of those born in 1921 or earlier was interviewed in 1993 and again in 1995. In 1998 these two samples were merged and two additional cohorts were added making the sample population approximately representative of the U.S. population ages 50 or older. A refresher cohort was added in 2004 to maintain representation of the population in their 50s. We restrict our analyses to data from 1998 to 2006 so that we have a full age range of individuals from which to draw and more consistent sets of questions with respect to health care costs.

Another reason for considering just years since 1998 is that, as noted above, the original sample was restricted to the non-institutionalized population. In the early years of data from any cohort, health care expenditures (both overall and out-of-pocket) are likely to be biased downward because those in nursing homes, who likely have the largest expenses, are excluded. ${ }^{12}$ Over the longer term, this bias is attenuated as the sample matured and the formerly noninstitutionalized elderly began to enter nursing homes.

The HRS is unusual in that when sample members die, it conducts what is termed an "exit interview." The exit interview is a survey administered to a surviving spouse (if available) or other knowledgeable individual (such as an adult child), and collects information about the deceased individual pertaining to the period of time since the previous "live" survey. ${ }^{13}$ Because we are concerned with the cost of health care in the time period near death, these exit interviews

\footnotetext{
${ }^{11}$ The 2010 wave is currently in the field.

${ }^{12}$ This problem is likely to be most severe in the older AHEAD cohort and less problematic for cohorts entering the sample in their 50 s when nursing home use is rare.

${ }^{13}$ Depending on the year, somewhere in the neighborhood of 35 percent of proxies are the surviving spouse.
} 
are central to our study and we focus our attention on them. However, we rely on the prior core survey for information about income and wealth of the household.

The HRS collects a great deal of information on financial status, health measures, and out-of- pocket medical expenses, all of which we use in our analyses. In an improvement over past surveys, the HRS uses a bracketing method to reduce the number of missing values. If a respondent does not know (or does not wish to provide) an answer to a particular question about the amount of a health care expenditure (or other dollar-denominated question), they are asked a series of questions as to whether the amount is greater than or less than a specific value. This strategy provides us with a specific range of values rather than a missing response. Although the exact amounts are still uncertain (and for some uses must be imputed) these brackets are vastly more useful than the missing values that characterize much of survey data, particularly in cases where proxy respondents may not know exact amounts.

We examine nine separate components of spending: insurance premiums (including privately purchased health insurance, "medigap" plans, employer provided insurance, Medicare HMOs, Medicare Part B, and long term care insurance), prescription drugs, physician payments, hospital and nursing home care, ${ }^{14}$ other medical care (including expenses not covered by insurance, such as medications, special food, equipment such as a special bed or chair, visits by doctors or other health professionals - and after 2002, special expenses such as in-home medical care/special facilities or services/in-home medical care), home health care, informal "helper" caregivers at home, non-medical spending (such as modifying the house with ramps or lifts,

\footnotetext{
${ }^{14}$ Nursing home and hospital expenditures were measured jointly in the HRS in 1998 and 2000 but separately thereafter. For consistency across waves we combine them in all years but note that where the distinction is made, nursing home expenditures account for the majority of spending.
} 
hiring help for housekeeping or other household chores or for assisting with personal needs), and hospice care.

Both the bracketed responses and the remaining missing values for individuals who cannot or will not provide even a range of values necessitate the use of an imputation strategy to provide exact values. While the HRS and RAND provide imputed values for many variables in the core interview for the full range of survey years, they ceased imputations for the exit interviews in 2000. An important component of our analysis is thus the construction of these values.

The imputation procedures and our methodology for handling outliers are central to our study. ${ }^{15}$ Our primary objective was to ensure that the information provided in the survey ends up in the final dataset with as little ad hoc restrictions and exclusions as possible. We consider three of the key issues below.

Reasonable caps on spending values. Large reported values for specific spending measures pose a problem for researchers because it is often impossible to discern whether the answer was given in error or whether it represents a rare but very large actual cost. Problems can also arise because of confusion about the appropriate time frame for the question. In the majority of cases respondents are asked to report out of pocket expenditures since the previous interview, but for a few expenditure items they are asked about monthly expenses (e.g. for helpers they are asked about payments in the last month and for prescription drugs, about average monthly payments). On the one hand, this change in the relevant period can confuse respondents and may lead to overstated medical expenses if, for example, when asked about monthly health

\footnotetext{
${ }^{15}$ The STATA programs used for the imputation are available on request.
} 
expenditures, respondents report the total expense since the last interview, thus raising the prospect of Type 1 error - overstating medical expenses. On the other hand, we know that outof-pocket expenditures are marked by a high degree of skewness, so ad hoc "second-guessing" the respondent might lead to Type 2 error - rejecting the high reported cost when it is in fact true.

The first column of Table 1 provides a summary of the caps we use for spending measures that seem unreasonably high. ${ }^{16}$ We based the $\$ 2,000$ cap on monthly health insurance payments for long-term care on premiums available through the Federal Long Term Care Insurance Program. ${ }^{17}$ There are fewer guidelines for pharmaceutical payments, but drug regimens for high-end specialty drugs such as Gleevic alone can run as much as $\$ 40,000$ annually, and so we set (somewhat arbitrarily) a cap of $\$ 5000$ per month in out-of-pocket pharmaceutical spending. ${ }^{18}$ (If we were to examine spending beyond 2006, we would want to limit pharmaceutical expenditures further because of the institution of Part D Medicare coverage.) We have much less evidence on private-pay physicians, but choose a maximum payment of 20 visits per month at $\$ 250 /$ visit.

\footnotetext{
${ }^{16}$ All expenditures are scaled to a monthly amount and capped at that level, then inflated to the appropriate time period.

${ }^{17}$ We assumed an 80-year-old was purchasing long-term care insurance with a $\$ 250$ maximum daily amount for a five-year maximum benefit period and $4 \%$ inflation adjustment; the monthly payment was over $\$ 1100$ for one person alone. See https://www.Itcfeds.com/ltcWeb/do/assessing your needs/RateCalcPlanChange. This amount does not include other insurance premiums (such as Medicare Part B premiums). While payments of $\$ 2000$ a month are thus possible, it is difficult to imagine valid reports much beyond this amount.

${ }^{18}$ Under the 2006 Medicare Part D program, there are limits on out-of-pocket exposure, but even with the Part D plan a recent General Accounting Office study called attention to the rising out-of-pocket spending on Gleevic and other drugs arising from the "doughnut hole" in coverage. See http://www.gao.gov/products/GAO-10-529T.
} 
Monthly maximum expenditures for helpers and home health care comes from the use of multiple-shift nursing care for (e.g.) people with advanced dementia. We assume a maximum of $\$ 15,000$ per month ( $\$ 25$ per hour times 20 hours per day times 30 days) for each category. The average monthly rate in New York City (the most expensive region) for a private nursing home bed is equal to just under $\$ 12,000$ per month, ${ }^{19}$ so we view a $\$ 15,000$ fee as a reasonable upper limit on what might be spent in a more expensive facility. Hospital expenditures and other expenses can clearly exceed $\$ 15,000$ monthly, but for consistency we simply set that as the maximum as well and use a cap of $\$ 30,000$ when nursing home and hospital expenses were reported together. (Recall that these are out of pocket costs incurred beyond what Medicare or other insurance has covered.) Finally, we set hospice care and non-medical spending to a monthly limit of $\$ 5,000 .^{20}$

One further problem is that questions about helpers and home health care refer to the month prior to death. It seems unreasonable to expect that these expenses were incurred at the same rate stretching back to the previous interview, but it also seems unreasonable to assume these costs were incurred just for one month. Based on a study of (post-1997) median length of stay for home health care Medicare patients (Murkofsky, 2003), we assume that both helpers and home health care workers are employed for 4 months in total.

\footnotetext{
${ }^{19}$ http://www.longtermcare.gov/LTC/Main Site/Paying LTC/Costs Of Care/Costs Of Care.aspx

${ }^{20}$ We also inspected many of the outliers more closely, examining, for example, expenditures in relation to the individual's income, wealth, and insurance coverage. We decided that a fixed rule was preferred relative to making ad hoc changes on an individual level. Our inspection of the data and investigations into examples of extremely expensive services available to individuals did, however, serve to demonstrate how difficult it can be to identify true reporting errors.
} 
Table 1 further illustrates the impact of these adjustments on specific components of spending. ${ }^{21}$ The caps matter the most for helpers (103 people out of 6631 , or 1.6 percent), but the mean difference in the spending measure (between the uncapped and capped values) is just $\$ 157$ because so few individuals report positive values. Other important categories affected by the caps are health insurance (25 people, reducing the average by \$193) and nursing home expenses (17 people, reducing average expenses by $\$ 424){ }^{22}$ In sum, the caps reduce average spending by less than $\$ 1000$ per person, but likely to scale back the variance by much more. Below, we consider the importance of further capping spending on the $95^{\text {th }}$ or $99^{\text {th }}$ percentile.

Sparse Imputation Values: One of the strengths of the HRS's questioning procedures for health care costs is its use of detailed categories of expenditures. This detailed probing likely captures more expenditure than would a general catch-all question and is useful to an analyst seeking to examine particular forms of spending. However, it also means that the distributions of spending for each of the underlying components are often plagued by small samples, particularly at the upper tails. In any given exit interview there are only 1200 or so deaths so for infrequent but important outcomes, such as the out of pocket expense associated with a stay in a nursing home or use of hospice care, there are many fewer observations in a given year.

\footnotetext{
${ }^{21}$ The HRS oversampled a number of specific groups so population weights are necessary in measuring representative points of the distribution (or mean values). In table 1 we report unweighted statistics to demonstrate clearly the effect of our caps. These means will therefore not correspond to the weighted means presented in subsequent tables. Population weights are zero in the exit interview, because the individuals are, well, dead. We therefore went back for up to three successive waves of the HRS core interviews to search for the most recent individual weight which was then assigned to the individual. Still, there were a few individuals (325 of the 6631 combined sample of decedents) with zero weights. We use these "zero weight" individuals in our imputation procedures but do not include them in the population totals.

22 Note that the sample size of 4032 is just for years 2002-06 when nursing home expenditures were reported separately from hospital costs.
} 
The thinness of the data makes it difficult to impute values using conditional means or a traditional hot-decking procedure. In the cases in which a specific bracket is available, say that spending on a particular service was between $\$ 10,000$ and $\$ 25,000$, we might be comfortable with imputing a value equal to the midpoint $(\$ 17,500)$ or even the mean over continuous responses in the interval, despite it being based on a small number of continuous responses (i.e. the scope for error is relatively small when bounds are in place). However, there are many cases in which we have opened rather than closed brackets. Individuals could report that they spent more than (say) $\$ 25,000$ on a health expense but not report an exact amount or any upper limit. Should we impute $\$ 26,000$ ? Or double that? With relatively few decedents in any given year, there may not be more than a handful of people who report values above the upper break point for any given component of spending, making it extremely difficult to impute an overall conditional mean, much less one tailored to individual specifics such as age or insurance coverage.

To deal with the sparseness of observations, we impute values based on a distribution constructed from a combined sample of exit interviews for all survey years, a much larger sample of 6,631. We first construct a combined file of exact dollar amounts for each spending category, with all measures adjusted for inflation using the GDP deflator and expressed in 2006 dollars. For everyone reporting a bracketed amount, we estimated the conditional mean for that bracket, including open ended brackets. Because of inflation, the end-points of the brackets vary over time, and so for each specific set of brackets, a new conditional mean was estimated. We then considered the more complex sets of questions - for example whether people reported positive amounts (but didn't know the amount) in which case they were assigned the mean value 
conditional on a positive value, or whether people reported not knowing at all whether the expense was incurred, in which case they were assigned the unconditional mean.

An example of the distribution is shown in Figure 1 for the $(\log )$ distribution of hospital and nursing home out-of-pocket expenditures for the entire sample, conditional on a positive amount. These estimates include both imputed and actual estimates, and while there are clear spikes where imputations play a larger part (or reflect rounding by respondents), there is sufficient density of continuously reported variables to suggest a log-normal distribution that is not dominated by outliers.

We recognize that in stacking data from all years of the survey to conduct our imputation procedure, we are missing any evolution over time in the distribution of expenditures. However, we believe that the potential bias introduced by this method is less of a problem than any bias introduced by relying solely on the few continuous data reports available in any particular year. We note that this procedure restricts our ability to assess growth in expenditures over time (other than that stemming from a rise in the number of individuals reporting values in the upper brackets or for those reporting actual expenses) and therefore do not provide a discussion of differences in spending by year. ${ }^{23}$

Time to Death: A final data issue which we note here is the differing length of time between interviews, particularly for exit interviews where the date of death might be just a few months after the last interview or as long as two years. If deaths are randomly distributed across a two year interval, the varying length of time will not affect our population averages. (The

\footnotetext{
${ }^{23}$ We have considered using the stacked sample along with regression equations to control for individual characteristics, but even with the full complement of decedents any regression would be sensitive to outliers.
} 
average time elapsed, from the respondents' final "live" interviews until their deaths, is approximately 15 months, with a median of 14 months.) There will, however, be systematic variation in expenditures with those who die long after their last interview appearing to have higher end-of-life costs than dying soon after the last survey simply because the costs pertain to a longer time period.

There may also be potential biases in reporting patterns as proxies may be more likely to misreport or forget completely about costs when the death occurred a year or more before, or because of upticks in spending very near death. It is difficult to sort out the difference between forgetfulness and a diminished rate of out-of-pocket expenditures as one goes further back in time prior to the death. And as we show, the flattening out of reported spending beyond a twoyear limit is suggestive of a sharp drop-off in recall for these proxies. We present data that has been adjusted for a quartic in the number of months since the last interview, whether for mean expenditures or quantile regressions (to estimate weighted percentiles), where we set the number of months to 12 .

\section{Results}

We use data from the 1998 - 2006 exit interviews, with a combined sample of 6,631 people (6,306 of whom have positive sampling weights). Table 2 presents summary statistics for the sample of decedents both combined and for individual years. The sample of decedents is, unsurprisingly, quite old. The average age at death is 79.4 , with just 12 percent of the decedents under the age of 65 . The fraction of men in the sample is somewhat below 50 percent, while average years of schooling are roughly 11 years, with a strong secular trend that rises from 10.6 years (1998) to 11.6 years (2006). The fraction of people who report their race as nonwhite 
ranges between 11 and 15 percent (depending on the year), while the percent Hispanic is 4.6 percent over the entire period.

Average out-of-pocket expenditures for the entire sample are $\$ 12,120$. There is some evidence of a rising trend over time (from $\$ 11,183$ in 1998 to $\$ 14,451$ in 2004) despite our imputation based on across year averages, but there is a marked decline between 2004 and 2006, to $\$ 12,954$. This decline is in part the consequence of a modest decline in out-of-pocket drug expenditures (probably more the consequence of a change in how the question is asked than in the introduction of Medicare Part D), but mostly because of an unusually high level of nursing home spending (conditional on admission) in 2004.

Wealth and income from the most recent interview prior to death are reported in Table 2. Net worth exclusive of housing wealth averages $\$ 178,469$, and including housing, $\$ 281,005$. The peak wealth estimates were in 2000 , and despite the subsequent downturn there is some hint of a modest positive trend over time. The averages, of course, mask the considerable variation (and skewness) across individuals; the median value of net worth excluding housing is $\$ 24,706$ (not shown), and for total net worth including housing wealth, the median is $\$ 102,000$. There is less skewness in income, however; average income is $\$ 31,713$, while median income is $\$ 19,177$. Table 3 a reports components of out-of-pocket expenditures and their mean, median, $90^{\text {th }}$, $95^{\text {th }}$ percentiles, and maximum amounts. While mean spending is $\$ 12,120$, median spending is just $\$ 5,175$. Indeed, nearly 30 percent of respondents reported less than $\$ 100$ in any out-ofpocket expenditure. (Whether this is because of under-reporting or a true lack of out-of-pocket costs is not entirely clear.) For the $90^{\text {th }}$ percentile, spending was $\$ 29,790$, the $95^{\text {th }}$ percentile $\$ 49,751$, the $99^{\text {th }} \$ 101,581$ (not shown), while the maximum was $\$ 331,825$. The impact of 
extreme outliers on the mean was fairly modest; capping spending at the $99^{\text {th }}$ percentile amount reduced the mean to $\$ 11,690$, while capping at the $95^{\text {th }}$ percentile reduced the mean to $\$ 10,400$.

As noted previously, nursing home and hospital out-of-pocket expenditures were the single largest category, with a mean of $\$ 4,731$, and $95^{\text {th }}$ percentile expenditures equal to $\$ 26,136$. Expenditures for insurance were less skewed (median of $\$ 990$, mean of $\$ 2,096$ ), while drug expenditures were somewhere in the middle; median spending was $\$ 448$ but the $95^{\text {th }}$ percentile was $\$ 6,000 .^{24}$

Payments to helpers for home-based care can account for substantial expenditures, although it is not a common expenditure category. ${ }^{25}$ Fewer than one-quarter of the respondents paid money to someone who helped with tasks around the home, but the conditional mean is high, adding \$1,281 to average expenses near death. Given our assumption that helpers spent no more than 4 months prior to death with the households, this estimate is likely to underestimate the overall uncertainty arising from such costs. Finally, hospice care is largely covered by Medicare, and thus its contribution to out-of-pocket expenditures is remarkably modest (\$38 on average).

The variation across individuals in these expenditures could be overstated given that the sample comprises both people who died more than two years after the prior core survey (and so

\footnotetext{
${ }^{24}$ Note that the maximum values simply reflect our imposition of caps. They may also be a downward biased measure of needed treatment if individuals fail to fill prescriptions because of cost.

${ }^{25}$ These values are reported in a section of the survey separately from medical expenditures. One potential concern is that they could therefore overlap with home care expenditures already reported in the main interview. We investigated this issue but is does not appear to be a problem as there was little correlation between the two. There were many cases in which individual's reported paying money to helpers but did not report any formal home health care.
} 
we're collecting unusually high levels of spending) and people who died within a few months of the survey (so we only pick up modest levels of spending). Figure 2 shows the association between total out-of-pocket expenditures and the time since the last core survey. Also presented is the implicit incremental spending - that is, the difference between the current average expenditures for people who died (say) between 7 and 9 months, minus expenditures for those who died between 4 to 6 months. (Thus we assume that the two groups are otherwise identical except for the time since the last interview - perhaps a strong assumption, but not an unreasonable one given the randomness of the interview dates relative to death).

Figure 2 demonstrates that a large fraction of spending in the last two years occurs in the last 6 months, although spending continues to climb to an average of nearly twenty thousand dollars for people whose last interviews were more than 2 years prior to death. That incremental spending falls off so much in later months is suggestive of recall bias, but further modeling would be required to measure and correct for recall bias.

To adjust for these clear differences in expenditures by months since the last interview, we present results that correspond to Table 3a of the distribution of spending, but adjust for the number of months since the interview by using a quartic in months, and setting the value(s) equal to 12 months prior to death. Regression results (from both weighted least squares and weighted quantile regressions) are presented in Table $3 \mathrm{~b}$. The mean values are similar, and the magnitude of the shrinkage at the $95^{\text {th }}$ percentile is quite modest or even non-existent in some cases. The impact of the shrinkage is greatest at the very top of the distribution - for example, as noted above the $99^{\text {th }}$ percentile of unadjusted total out-of-pocket expenditures is $\$ 101,581$, but the adjusted measure is $\$ 94,310$. In sum, these 12 -month measures are more accurate estimates of 
the true distribution of out-of-pocket expenditures, but even after these corrections, the true variation in medical expenditures is still substantial.

We next consider the association between out-of-pocket expenditures and wealth and income quintiles. Table $4 \mathrm{a}$ presents detailed spending measures by wealth quintile, and Table $4 \mathrm{~b}$ shows equivalent measures by income quintile. The mean values are not exactly the same as in the aggregates reported in Table 3 because the sample changes somewhat due to missing values for either income (resulting in a sample size of 5,775) or wealth $(\mathrm{N}=6,089)$. Total out-of-pocket expenditures for decedents rise from $\$ 7,173$ in the bottom wealth quintile to $\$ 18,233$ in the top quintile, an increase of 154 percent. All measures of spending exhibit a positive wealth elasticity, but some are larger in magnitude than others. For example, while nursing home and hospital expenditures are nearly double for the highest quintile compared to the lowest quintile of wealth $(\$ 6,521$ versus $\$ 3,461)$, the largest proportional differences arise in care provided at home, for example home care $(\$ 1,334$ versus $\$ 383)$, non-medical expenditures $(\$ 1,416$ versus $\$ 335)$ and helper costs $(\$ 2,601$ compared to $\$ 547)$.

There are similar associations between spending and income, but as shown in Table 4b, they are much less pronounced. Overall spending rises from $\$ 9,046$ in the bottom quintile to $\$ 14,269$ in the top quintile, with patterns similar to those for wealth apparent with respect to spending on home care, non-medical care, and helper costs. Also of interest are the categories that are not associated with income, for example hospital and nursing home expenses; these are $\$ 4,022$ for the lowest income level and $\$ 4,471$ for the highest. In part this is because lower income decedents were more likely to have experienced a nursing home admission (11 percent compared to 7 percent for the highest income group) increasing the unconditional mean. That said, it does not appear that one commonly offered explanation for income-based differences in 
out-of-pocket spending - the use of luxury nursing homes - receives much support from the data. $^{26}$

We further consider a multiple regression model of spending as a function of observable characteristics to disentangle separate effects of income and wealth on expenditures. We control for sex, race, Hispanic identification, a quadratic in schooling, a cubic in age, and (as before) control for months prior to the previous core interview. Figure 3 presents just the predicted measures of out-of-pocket total expenditures, evaluated at the mean values of the explanatory variables and the assumption of a 12-month value for months since last interview. The regression results indicate that out-of-pocket expenditures are roughly twice as high in the top wealth quintile compared to the bottom wealth quintile (95 percent confidence intervals are shown by the whiskers in the diagram), but that the impact of income is no longer significantly different from zero. In sum, the estimates support the hypothesis that out-of-pocket expenditures are determined primarily by wealth on hand, and not by late-life income flows. This result accords with estimates presented in Smith (1999) that demonstrates a significant positive relationship between wealth and health status in the HRS, but no such relationship for retirement income and health.

Finally, we present raw measures of out-of-pocket expenditures broken down by wealth quintiles and by age group. We find a strong association between spending and age, as also noted by De Nardi, French, and Jones (2010), with a widening distribution of spending with wealth quintile at older ages. In Figure 4a, for example, end-of-life spending for those dying under age 70 is quite modest, but average expenditures rise rapidly so that for the highest wealth

\footnotetext{
${ }^{26}$ Nursing home admission rates come from the 2002-06 data. There may also be systematic differences in length-of-stay in nursing homes across income groups.
} 
quintile, even average spending at age $90+$ is over $\$ 30,000$ per year. And while this type of pattern is shown also for nursing home and hospitals expenditures (Figure 4b), it is most pronounced for home-related services - the sum of home health care, helpers, non-medical costs, and other medical expenses. While such spending barely budges with age for the lowest wealth quintile, it rises more than three-fold (from an average of $\$ 3,448$ to $\$ 11,594$ ) by age for the highest wealth quintile. This pattern is consistent with a greater likelihood of sudden-onset illnesses for younger decedents, rather than long (and expensive) chronic illnesses among the oldest old.

\section{Conclusion}

Previous studies of out-of-pocket expenditures have generally found low levels of average expenditures but a high degree of skewness in the distribution (Palumbo, 1999; Feenberg and Skinner, 1994; French and Jones, 2004). In part, the low mean values were the consequence of older data and generally lower levels of health care spending in those years. Our results suggest that, at least for the period 1998-2006, out-of-pocket expenditures near the end of life are both pervasive and large, particularly for higher wealth groups and at older ages. Even after adjusting for the variable length of time the decedents are in the sample, average out-of-pocket expenditures in the last 12 months of life are $\$ 11,618$, with a median of $\$ 5,061$ and a $95^{\text {th }}$ percentile measure equal to $\$ 49,907$. These numbers at least appear to be large relative to the decedent's median non-housing wealth $(\$ 24,706)$.

We have also found a strong wealth elasticity of spending, which adds some nuance to the notion of health expenditure shocks. Given that our sample consists of recent decedents, it would be hard to argue that the health "shock" experienced by the lowest wealth individual is 
much different from that shock experienced by the highest wealth group. It may therefore be tempting to view all of these wealth-elastic expenditure choices as "luxury" spending, like purchasing a Lexus rather than a Kia. ${ }^{27}$ In this view, the low-wealth-quintile spending measure would represent the "true" shock to spending and all the rest is deemed endogenous, and thus perhaps not relevant for coverage under social insurance programs.

However, it may well be that the lowest wealth group as unable to afford uninsured but medically valuable commodities- as one might expect for a group reporting zero median net wealth and an income of less than $\$ 10,000$ - and that no spending is therefore observed for these needed items. Similarly, those with low income or wealth may only be able to afford lower quality care. For example, Mor et al. (2004) showed much lower levels of quality - as measured by the prevalence of high-risk pressure ulcers, restraint use, and lack of pain control - in nursing homes catering largely to Medicaid patients. ${ }^{28}$

Indeed, the ultimate luxury good appears to be the ability to retain independence and remain in one's home (perhaps altered to permit easy navigation), through the use of (paid) helpers and home health care assistance. Once admitted to the nursing home, a further benefit of assets is the ability to eschew Medicaid, which many would prefer to avoid (Ameriks, et al., 2010), and to have the ability to purchase more comfortable living arrangements. These types of expenses are generally not amenable to insurance coverage, and thus it is not surprising that only those with sufficient accumulated wealth can afford high levels of spending; levels that are large relative to even high flows of income. Our results are thus consistent with the view that many

\footnotetext{
27 For a model of endogenous out-of-pocket health care expenditures, see De Nardi, French, and Jones (2010).

${ }^{28}$ This finding contrasts with the view of Hurd and Rohwedder (2009) who state that "[b]ecause of Medicaid, amounts spent by a single person on long-term end-of-life stay have practically no value." (p.3)
} 
elderly may continue to hold (or even accumulate) wealth as a hedge against uninsured costs surrounding expensive end of live care-giving for themselves or their spouse.

The independent living arrangements facilitated by wealth could also have long-term effects on survival and functioning. Although the evidence on this issue is sparse, one randomized trial did suggest that specialized home nursing improves survival following cancer treatment (McCorkle, et al., 2000). While this result applies to a fairly specialized form of home care, it is consistent with the idea that wealth can translate into better health through these types of (uninsured) mechanisms. Certainly many patients themselves would testify that they will fare better if allowed to remain in their own home. Finally, items such as special food or home accommodations likely affect health directly, for example by reducing falls or other injuries.

There are several important limitations of this study. First, we recognize the inherent uncertainty surrounding many of the assumptions about limits on spending, whether monthly caps or the length of time we might expect spending to have occurred (e.g., for helpers). That said, we believe that even with our conservative imputations, there is strong evidence of substantial pockets of out-of-pocket expenditures in the data, estimates that are consistent with aggregate measures of out-of-pocket spending. Furthermore, large differences exist by ability to pay. Even if we cap total out-of-pocket spending at the $95^{\text {th }}$ percentile value to limit the impact of outliers, we find dramatic differences in spending by wealth.

Second, we have not adequately captured non-monetary care-giving by family members that may be provided out of affection, or alternatively, motivated by inheritances or other transfers. Past studies suggest that value of this unpaid care is far greater than that of formal paid care. Furthermore, this unpaid caregiving may well be concentrated in the lower tails of the 
income and wealth distributions and may offset some of the differences we observe with respect to expenditures on in-home care.

Third, our focus on end-of-life spending reflects only the last year or so of life, and does not capture lifetime risks (as in Palumbo, 1999; Webb and Zhivan, 2010; or De Nardi, French, and Jones, 2010). Nor do we capture the important risk of disabling health shocks for those still working. During a 10-year period for people in their 50s, seven out of ten adults developed health problems, lost their jobs, or lost spouses owing to divorce or death (Johnson, Mermin, and Uccello, 2006; also see Smith, 2005). Such losses would lead to much diminished wealth and income as just as individuals are approaching retirement age.

Despite these qualifications, we believe that this study sheds important light on the role of medically related expenditures in affecting the resources of the elderly. This issue is of substantial policy concern particularly as we consider health care reform, changes in the provision of care, and the much debated question whether those retiring today have adequate savings and insurance to cover future health care needs (Skinner, 2007). Understanding the nature of risks and more importantly, the health-based value of these out-of-pocket expenditures - as opposed to their pure consumption value -- is central to designing future social insurance policies to temper their burden. 


\section{References}

Ameriks, John, Andrew Caplin, Steven Laufer, and Stijn Van Nieuwerburgh (forthcoming), "The Joy of Giving or Assisted Living? Using Strategic Surveys to Separate Public Care Aversion from Bequest Motives" Journal of Finance.

Arno, Peter, Levine, Carol, and Margaret Memmott 1999. The Economic Value of Informal Caregiving, Health Affairs 18 (2) : 182-188.

De Nardi, Mariacristina, Eric French, and John B. Jones, February 2010. Why Do the Elderly Save? The Role of Medical Expenses. Journal of Political Economy 116(1): 39-75.

Dranove, David, and Michael L. Millenson, March/April 2006.Medical Bankruptcy: Myth Versus Fact. Health Affairs 25(2): w74-w83.

Feenberg, Daniel, and Jonathan Skinner, November 1994.The Risk and Duration of Catastrophic Health Care Expenditures. Review of Economics and Statistics 76(4): 633-47.

Finkelstein, Amy and Kathleen McGarry, 2005. Private Information and its Effect on Market Equilibrium: Evidence from the Long-Term Care Insurance Market. The American Economic Review 96(4): 938-958.

French, Eric, and John Bailey Jones, 2004. On the Distribution and Dynamics of Health Care Costs. Journal of Applied Econometrics 19(6): 705-721.

Fronstin, Paul, July 2006. Savings Needed to Fund Health Insurance and Health Care Expenses in Retirement. Employee Benefit Research Institute Issues Brief No. 295

Fronstin, Paul, and Paul Yakoboski, July 2005. Options and Alternatives to Fund Retiree Health Benefits. TIAA-CREF Institute Policy Brief.

Goldman, Dana, and Julie Zissimopoulos, 2003. High Out-of-Pocket Health Care Spending by the Elderly. Health Affairs 22, no. 3 194-202 doi: 10.1377/hlthaff.22.3.194.

Goldman, Dana, and Julie Zissimopoulos, 2010. Medical Expenditure Measures in the Health and Retirement Study." Rand Corporation and the University of Southern California.

Hartman, Micah, Aaron Catlin, David Lassman, Jonathan Cylus, and Stephen Heffler, November 6, 2007. U.S. Spending By Age, Selected Years through 2004. Health Affairs doi: 10.1377/hlthaff.27.1.w1. For data see: http://www.cms.gov/NationalHealthExpendData/downloads/2004-age-tables.pdf 
Himmelstein, David U., Elizabeth Warren, Deborah Thorne, and Steffie Woolhandler, February 2, 2005. Illness and Injury As Contributors To Bankruptcy, Health Affairs Web Exclusive.

Hurd, Michael D. and Susann Rohwedder, September 2009. The Level and Risk of Out-ofPocket Health Care Spending, University of Michigan Retirement Research Center, Working Paper No 2009-218.

Johnson, Richard W., Gordon B.T. Mermin, and Cori E. Uccello, April 200 . How Secure are Retirement Nest Eggs? Center for Retirement Research at Boston College Issue Brief 45,

Kaiser Family Foundation, http://ehbs.kff.org/images/abstract/7814.pdf

McGarry, Kathleen and Robert Schoeni, 2005. Medicare Gaps and Widow Poverty Social Security Bulletin 66 (1): 58-74.

McCorkle, R., Strumpf, N., Nuamah, I., Adler, D., Cooley, M., Jepson, C., Lusk, E. \& Torosian, M., 2000. A randomized clinical trial of a specialized home care intervention on survival among elderly post-surgical cancer patients. Journal of the American Geriatrics Society 48, 1707-1713.

Merlis, Mark, Douglas Gould, and Bisundev Mahato, February 2006. Rising Out-of-Pocket Spending for Medical Care: A Growing Strain on Family Budgets. The Commonwealth Fund.

Mor, Vincent, Jacqueline Zinn, Joseph Angelelli, Joan M. Teno, and Susan C. Miller, 2004. Driven to Tiers: Socioeconomic and Racial Disparities in the Quality of Nursing Home Care Milbank Memorial Fund Quarterly 82(2): 227-56.

Murkofsky, Rachel L., Russell S. Phillips, Ellen P. McCarthy, Roger B. Davis, and Mary Beth Hamel, June 4, 2003. Length of Stay in Home Care Before and After the 1997 Balanced Budget Act JAMA 289(21): 2841-2848.

New York Times, June 12, 2008. The Plight of the Underinsured.

Paez, Kathryn Anne, Lan Zhao, and Wenke Hwang, 2009. Rising Out-of-Pocket Spending for Chronic Conditions: A Ten-Year Trend Health Affairs 28(1): 15-25.

Palumbo, Michael G., 1999.Uncertain Medical Expenses and Precautionary Saving Near the End of the Life Cycle Review of Economic Studies 66(2): 395-421. 
Sing, M., JS Banthin, TM Selden, CA Cowan, and SP Keehan, Fall 2006. Reconciling Medical Expenditure Estimates from the MEPS and NHEA, 2002 Health Care Financing Review 28(1): $25-40$.

Skinner, Jonathan. Summer 2007. Are You Sure You're Saving Enough for Retirement? Journal of Economic Perspectives 59-80.

Smith, James P. 1999. Healthy bodies and Thick Wallets: The Dual Relation Between Health and Economic Status. Journal of Economic Perspectives 13 (2) : 145-166.

Smith, James P. 2005. Consequences and Predictors of New Health Events, in David A. Wise (ed.) Analyses in the Economics of Aging Chicago: University of Chicago Press and NBER.

Trejos, Nancy, December 7, 2008.With Out-of-Pocket Medical Expenses Rising, It Might Be Time for Insurance Change, The Washington Post p. F5.

Webb, Anthony, and Natalia Zhivan, February 2010. How Much is Enough? The Distribution of Lifetime Health Care Costs Center for Retirement Research at Boston College Working paper No. 2010-1. 
Figure 1: Distribution of Nursing Home and Hospital Expenditures: Combined 6 Waves

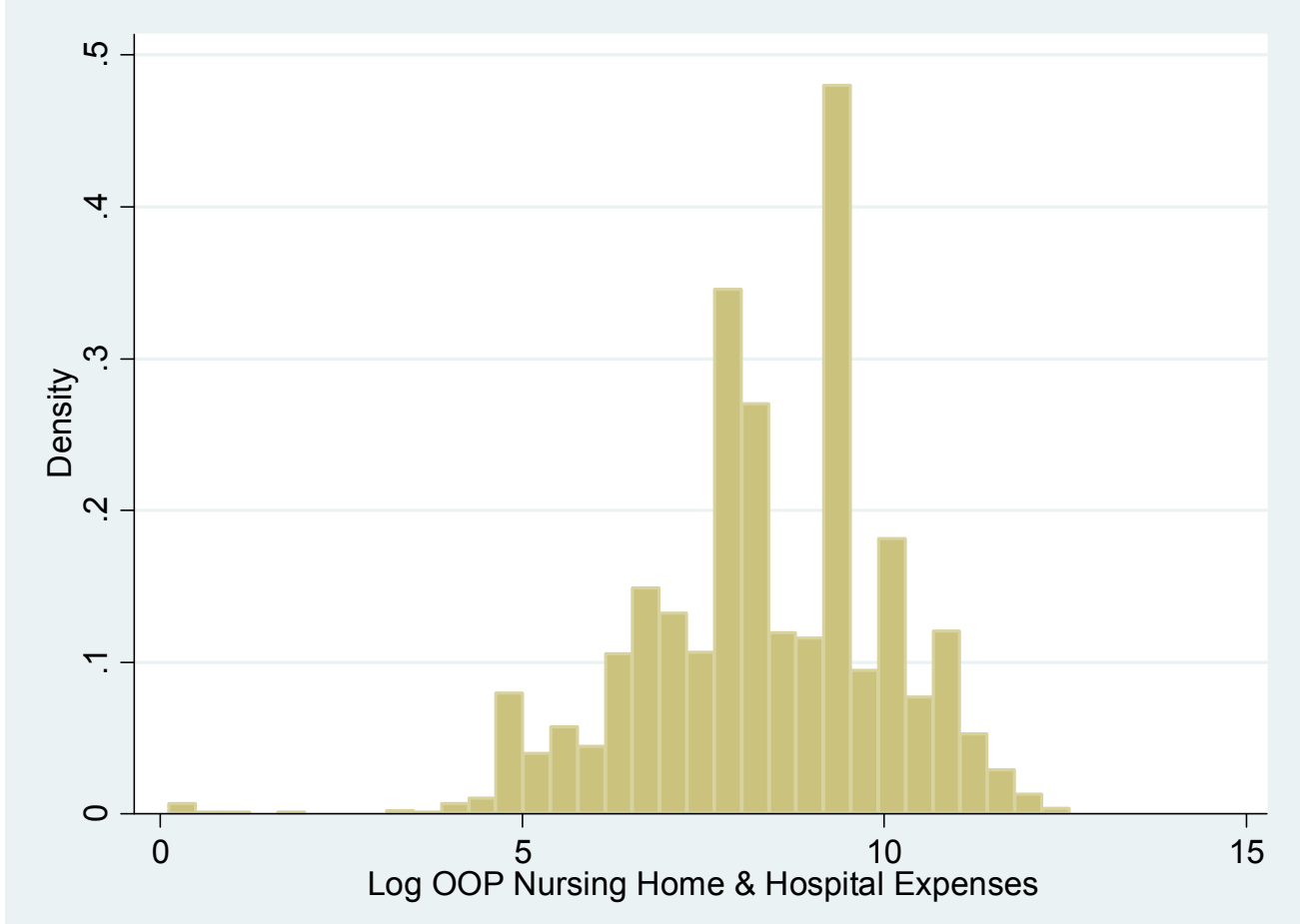

Figure 2: Average Out-of-Pocket Expenditures by Number of Months Between Last Interview and Time of Death

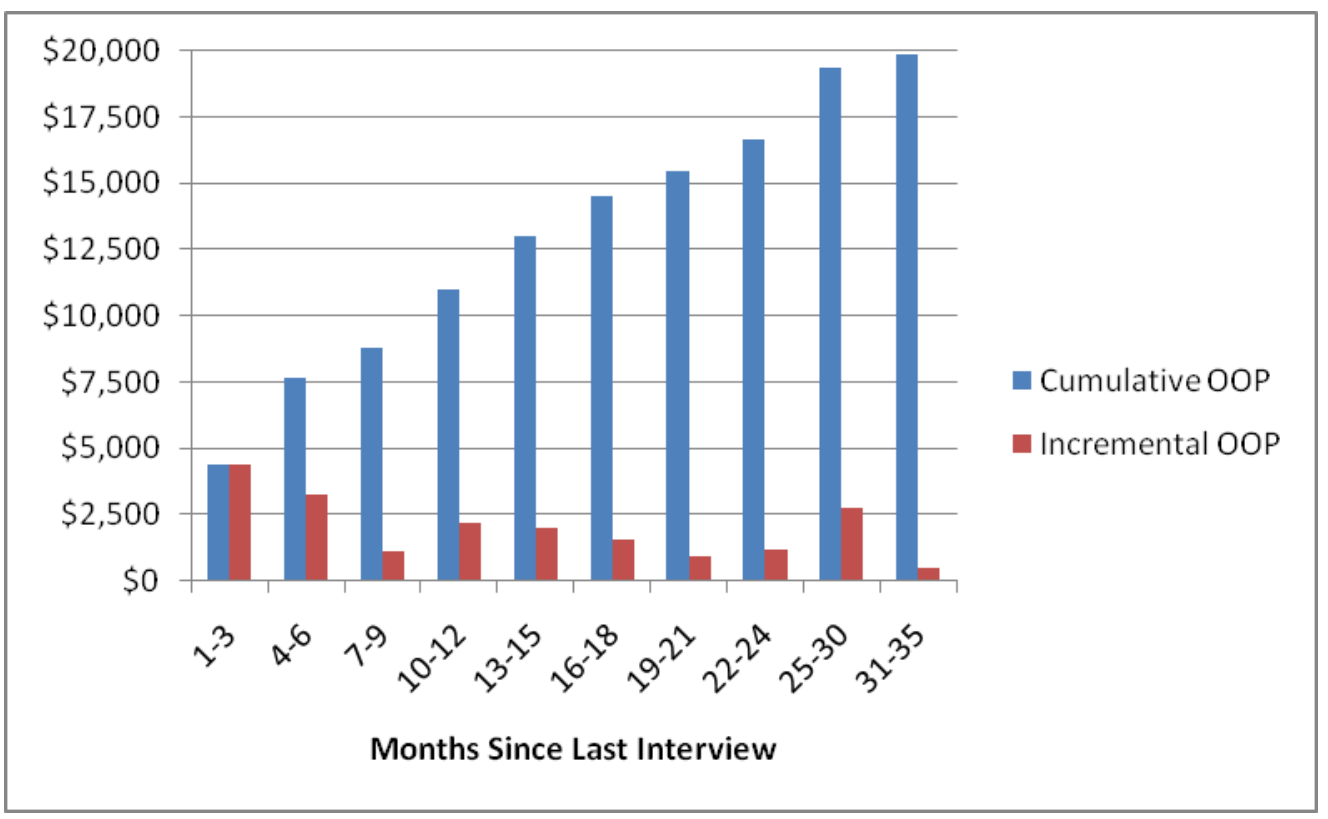


Figure 3: Adjusted Out-of-Pocket Expenditures, by Wealth and Income Quintile

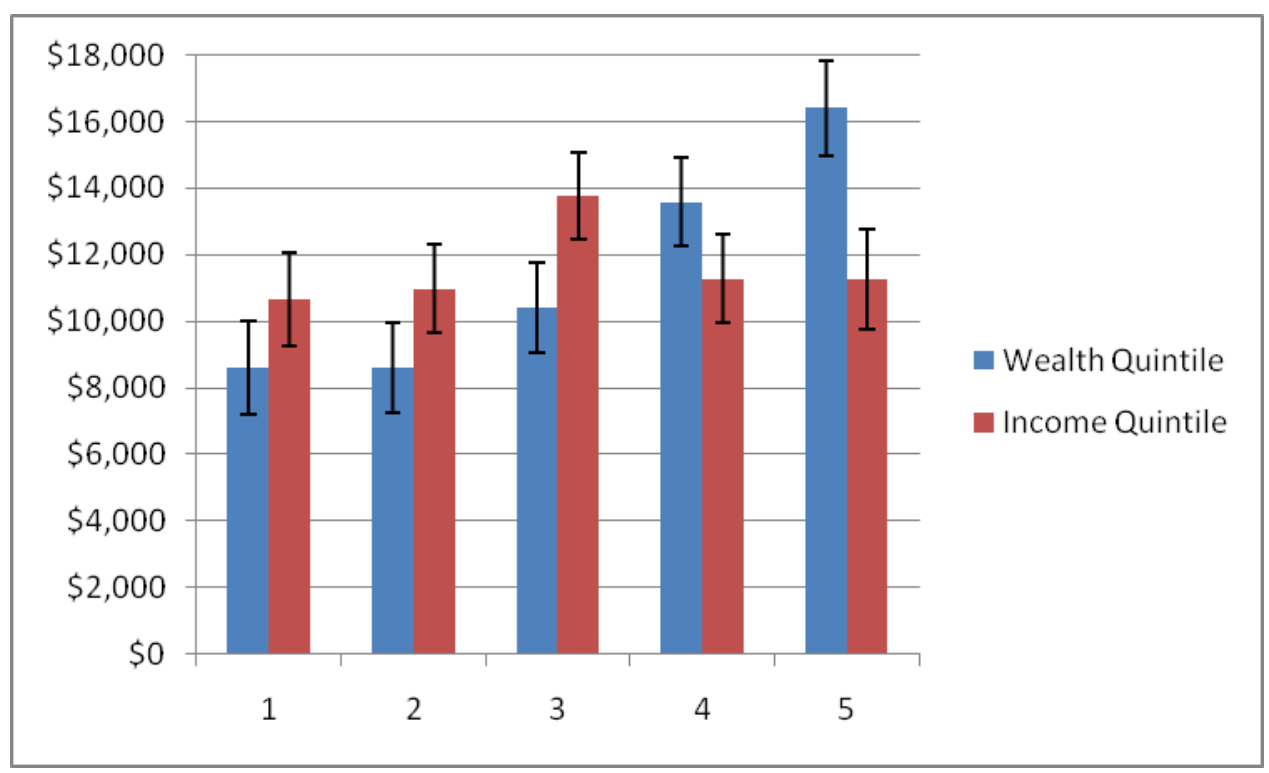

Note: Estimates are adjusted using mean values of sex, race, Hispanic identification, a quadratic in years of schooling, cubic in age, and quartic in the months between the last interview and the time of death (set to 12 months). Ninety-five percent confidence intervals are included.

Figure 4a: Total Out-of-Pocket Expenditures by Age at Death and by Wealth Quintile

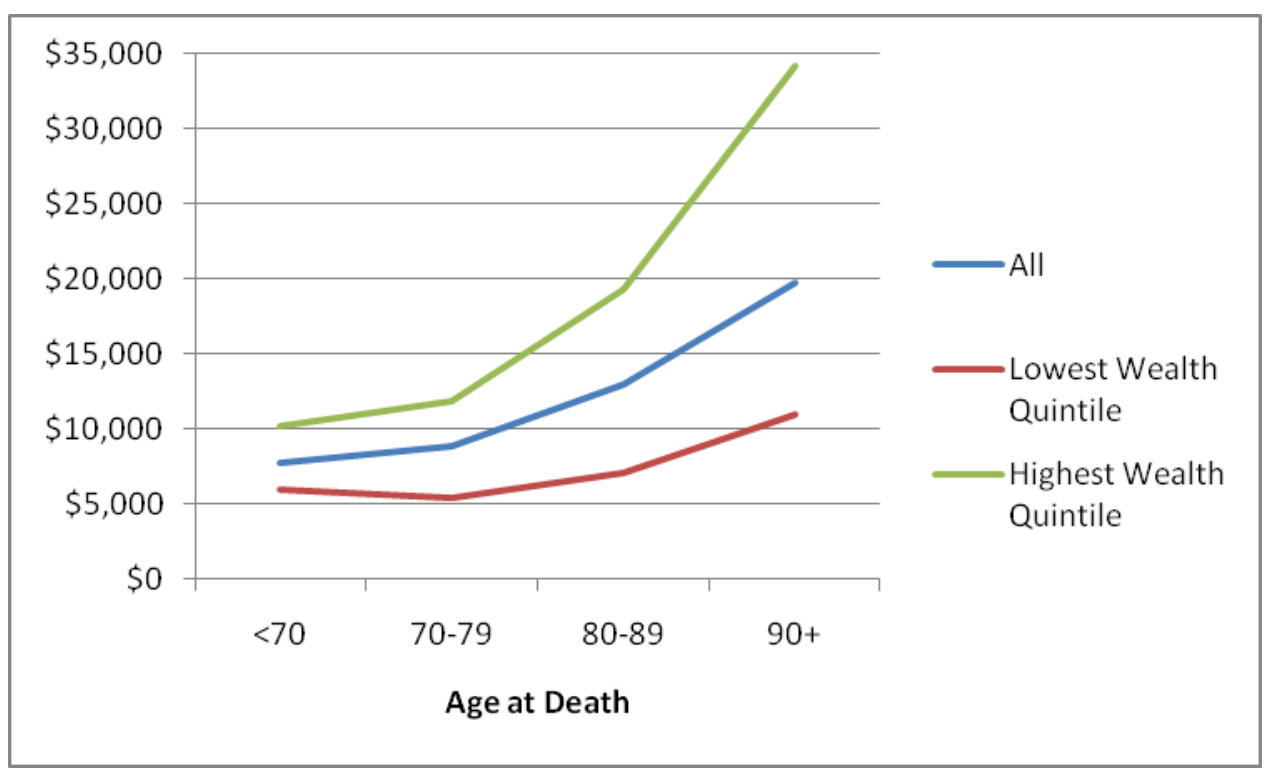


Figure 4b: Nursing Home and Hospital Out-of-Pocket Expenditures by Age at Death and Wealth Quintile

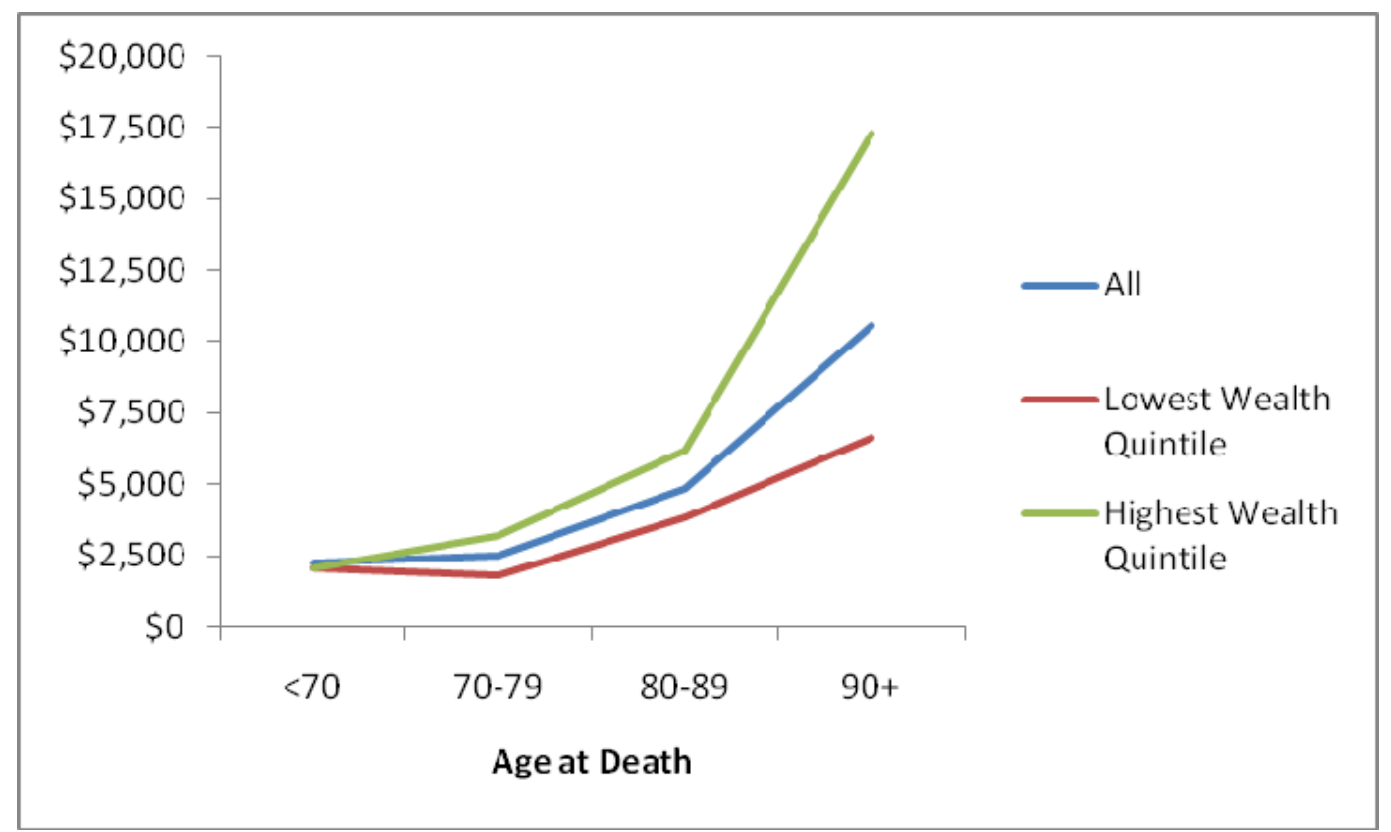

Figure 4c: Home-Related Services (Home Health Care, Helpers, Non-Medical Costs, Other Medical) by Age at Death and Wealth Quintile

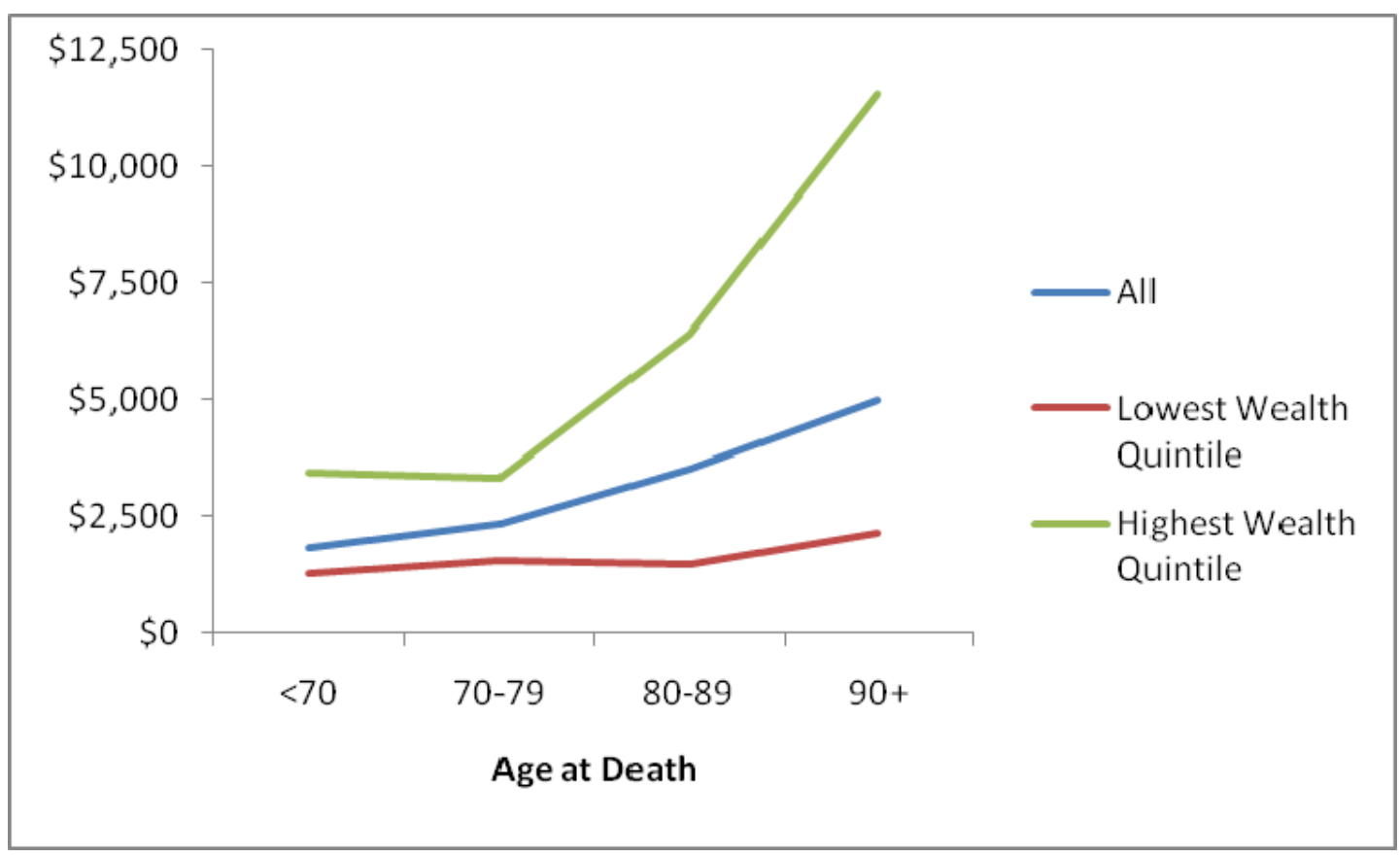




\section{Table 1: Monthly Caps on Expenditures}

\begin{tabular}{lccccc}
\multicolumn{1}{c}{ Variable } & Monthly & Fraction & Number & Unweighted & Unweighted \\
& Cap & $\begin{array}{c}\text { Affected by } \\
\text { cap }\end{array}$ & $\begin{array}{c}\text { Affected by } \\
\text { cap }\end{array}$ & $\begin{array}{c}\text { Mean prior } \\
\text { to cap }\end{array}$ & $\begin{array}{c}\text { Mean after } \\
\text { cap }\end{array}$ \\
Health Insurance & 2,000 & .0038 & $25 / 6631$ & 2063 & 1870 \\
Rx & 5,000 & .0009 & $6 / 6631$ & 1715 & 1628 \\
Doctor & 5,000 & .0002 & $1 / 6631$ & 390 & 389 \\
Home care & 15,000 & .0006 & $4 / 6631$ & 686 & 652 \\
Helpers & $15,000 *$ & .0155 & $103 / 6631$ & 1330 & 1173 \\
Other \& Special & 15,000 & .0002 & $1 / 6631$ & 388 & 388 \\
Hospital + Nursing & 30,000 & .0019 & $5 / 2599$ & 3840 & 3739 \\
Home & 15,000 & .0007 & $3 / 4032$ & 745 & 667 \\
Hospital & 15,000 & .0042 & $17 / 4032$ & 4807 & 4383 \\
Nursing home & 5,000 & .0000 & $0 / 6631$ & 51 & 51 \\
Hospice & 5,000 & .0003 & $2 / 6631$ & 871 & 846 \\
Non-medical & & & &
\end{tabular}

Note: * Maximum of 4 months. Total samples may be larger than those used in analysis because of additional selection criteria 
Table 2: Variable Means, Total and by Year 1998-2006

\begin{tabular}{|c|c|c|c|c|c|c|}
\hline & \multicolumn{6}{|c|}{ Year of Exit Interview } \\
\hline & $\begin{array}{c}\text { All } \\
(n=6631)\end{array}$ & $\begin{array}{c}1998 \\
(n=1253)\end{array}$ & $\begin{array}{c}2000 \\
(n=1346)\end{array}$ & $\begin{array}{c}2002 \\
(n=1497)\end{array}$ & $\begin{array}{c}2004 \\
(n=1227)\end{array}$ & $\begin{array}{c}2006 \\
(n=1308)\end{array}$ \\
\hline Age at death & 79.4 & 81.2 & 79.3 & 78.4 & 80.3 & 78.2 \\
\hline Sex $(1=$ male $)$ & 0.478 & 0.458 & 0.491 & 0.483 & 0.457 & 0.497 \\
\hline Years of schooling & 11.1 & 10.6 & 10.9 & 11.1 & 11.3 & 11.6 \\
\hline Nonwhite & 0.134 & 0.114 & 0.130 & 0.152 & 0.131 & 0.140 \\
\hline Hispanic & 0.046 & 0.035 & 0.038 & 0.057 & 0.043 & 0.053 \\
\hline Birth-year & 1921.6 & 1915.5 & 1919.6 & 1922.6 & 1922.8 & 1926.8 \\
\hline OOP expenditures & 12,120 & 11,183 & 10,610 & 11,396 & 14,451 & 12,954 \\
\hline $\begin{array}{l}\text { Net worth (less house } \\
\text { equity) in prior period }\end{array}$ & 178,469 & 165,669 & 204,122 & 178,312 & 153,664 & 187,990 \\
\hline Net worth in prior period & 281,005 & 235,321 & 326,529 & 283,570 & 252,988 & 299,829 \\
\hline Income in prior period & 31,713 & 20,286 & 34,506 & 33,726 & 33,322 & 35,681 \\
\hline
\end{tabular}

Notes: Sample sizes of specific means for net worth and income are slightly smaller in each year (and for the total) because of missing data. All wealth and income data are for the household in the prior interview wave. 


\section{Table 3a: Distribution of Expenditure by Category for Exit Interviews}

\begin{tabular}{|c|c|c|c|c|c|c|}
\hline Variable & Mean & Median & p 75 & p90 & p95 & Maximum \\
\hline Total OOP & 12,120 & 5,175 & 13,681 & 29,790 & 49,751 & 331,825 \\
\hline Insurance & 2,096 & 990 & 2,633 & 5,111 & 7,097 & 54,503 \\
\hline Drugs & 1,761 & 448 & 2,400 & 4,353 & 6,000 & 129,998 \\
\hline Physician & 353 & 0 & 387 & 1,137 & 1,211 & 51,957 \\
\hline Nursing Home/Hosp & 4,731 & 0 & 2,238 & 11,190 & 26,136 & 285,645 \\
\hline Other \& Special & 384 & 0 & 0 & 702 & 1,624 & 48,492 \\
\hline Home Health & 687 & 0 & 0 & 722 & 2,565 & 254,997 \\
\hline Non-Medical & 790 & 0 & 0 & 604 & 2,979 & 115,000 \\
\hline Helpers & 1,281 & 0 & 0 & 4,084 & 8,190 & 60,000 \\
\hline Hospice & 38 & 0 & 0 & 0 & 0 & 70,000 \\
\hline
\end{tabular}

Table 3b: Distribution of Expenditure by Category for Exit Interviews, Normalized to a Twelve-Month Period

\begin{tabular}{lrrrrrr}
\multicolumn{1}{c}{ Variable } & Mean & Median & p75 & p90 & p95 & p99 \\
\hline Total Oop & 11,618 & 5,061 & 12,890 & 29,335 & 49,907 & 94,310 \\
Insurance & 1,746 & 914 & 2,301 & 3,274 & 4,766 & 21,602 \\
Drugs & 1,496 & 580 & 2,384 & 2,811 & 5,082 & 11,679 \\
Physician & 335 & 0 & 462 & 1,143 & 1,218 & 3,120 \\
Nursing Home/Hosp & 4,975 & 0 & 2,303 & 12,046 & 27,770 & 75,902 \\
Other Medical & 387 & 0 & 0 & 728 & 2,040 & 7,382 \\
Home Health & 617 & 0 & 0 & 742 & 2,565 & 9,968 \\
Non-Medical & 721 & 0 & 0 & 687 & 2,761 & 13,749 \\
Helpers & 1,249 & 0 & 0 & 5,009 & 9,307 & 20,290 \\
Hospice & 51 & 0 & 0 & 0 & 0 & 220
\end{tabular}

Table $3 \mathrm{~b}$ reports fitted values for a 12 -month period from the prior interview period using a quartic in months. Definition of categories: Insurance premiums include premiums for Medicare Part B and long term care insurance as well as medigap and other privately purchased policies. Physician includes out-patient care in 2002-2006 interviews. Nursing home and hospital out-of-pocket expenditures are combined, but are available separately in 2002-2006 interviews. The Other Medical category includes "special" and "other medical" categories. Special being in-home medical care/special facilities or services, and other being "other expenses not covered by insurance, such as medications, special food, equipment such as a special bed or chair, visits by doctors or other health professionals, or other costs" Non-Medical is payments for items "such as modifying the house with ramps or lifts, hiring help for housekeeping or other household chores or for assisting with personal needs" 
Table 4a: Mean Values of Out-of-Pocket Expenditures, by Wealth Quintiles, and by Category of Payments

\begin{tabular}{|c|c|c|c|c|c|c|c|c|c|c|c|}
\hline $\begin{array}{c}\text { Wealth } \\
\text { Quintile }\end{array}$ & Total & Insurance & Drugs & Physician & $\begin{array}{l}\text { N. Home } \\
\& \text { Hosp. }\end{array}$ & $\&$ & $\begin{array}{l}\text { Other } \\
\text { Special }\end{array}$ & $\begin{array}{l}\text { Home } \\
\text { Care }\end{array}$ & $\begin{array}{l}\text { Non- } \\
\text { Medical }\end{array}$ & $\begin{array}{r}\text { Helper } \\
\text { Costs }\end{array}$ & Hospice \\
\hline 11 & 7,173 & 937 & 971 & 217 & 3,461 & & 306 & 383 & 335 & 547 & 17 \\
\hline 21 & 9,118 & 1,453 & 1,558 & 256 & 3,806 & & 252 & 359 & 607 & 813 & 13 \\
\hline 31 & 11,765 & 2,360 & 1,834 & 406 & 4,550 & & 366 & 636 & 553 & 978 & 82 \\
\hline 41 & 14,454 & 2,591 & 2,330 & 422 & 5,458 & & 424 & 753 & 1,028 & 1,431 & 18 \\
\hline 51 & 18,233 & 3,159 & 2,148 & 424 & 6,521 & & 571 & 1,334 & 1,416 & 2,601 & 60 \\
\hline Total | & 12,147 & 2,099 & 1,768 & 345 & 4,759 & & 383 & 693 & 788 & 1,274 & 38 \\
\hline
\end{tabular}

Table 4b: Mean Values of Out-of-Pocket Expenditures, by Income Quintiles, and by Category of Payments

\begin{tabular}{|c|c|c|c|c|c|c|c|c|c|c|c|}
\hline $\begin{array}{l}\text { Income } \\
\text { Quintile }\end{array}$ & Total & Insurance & Drugs & Physician & $\begin{array}{l}\text { N. Home } \\
\& \text { Hosp. }\end{array}$ & $\&$ & $\begin{array}{l}\text { Other } \\
\text { Special }\end{array}$ & $\begin{array}{l}\text { Home } \\
\text { Care }\end{array}$ & $\begin{array}{l}\text { Non- } \\
\text { Medical }\end{array}$ & $\begin{array}{r}\text { Helper } \\
\text { Costs }\end{array}$ & Hospice \\
\hline 11 & 9,046 & 1,127 & 1,382 & 210 & 4,022 & & 301 & 371 & 620 & 985 & 28 \\
\hline 21 & 10,347 & 1,681 & 1,495 & 243 & 4,358 & & 308 & 494 & 655 & 1,100 & 13 \\
\hline 31 & 14,002 & 2,261 & 1,788 & 336 & 6,316 & & 339 & 725 & 985 & 1,229 & 23 \\
\hline 41 & 12,545 & 2,564 & 2,200 & 383 & 4,092 & & 369 & 645 & 1,032 & 1,227 & 32 \\
\hline 51 & 14,269 & 2,832 & 1,946 & 527 & 4,471 & & 600 & 1,276 & 680 & 1,911 & 26 \\
\hline Total & 12,040 & 2,092 & 1,762 & 340 & 4,651 & & 384 & 702 & 794 & 1,290 & 25 \\
\hline
\end{tabular}

Notes: Definitions of specific categories in Table 4. Sample sizes are different $(\mathrm{N}=6089$ for the wealth quintiles and $\mathrm{N}=5775$ for the income quintiles) owing to missing values for wealth and income; hence the totals do not necessarily correspond to the statistics for the full sample. 